\title{
A model-based assessment of adaptation options for Chianti wine production in Tuscany (Italy) under climate change
}

\author{
Xueqin Zhu • Marco Moriondo • Ekko C. van Ierland • \\ Giacomo Trombi • Marco Bindi
}

Received: 28 June 2013/ Accepted: 14 April 2014

(C) Springer-Verlag Berlin Heidelberg 2014

\begin{abstract}
This paper covers a comprehensive economic analysis of climate change adaptation options for a specific wine producing region, namely Tuscany. As temperature increases under climate change, rainfall patterns will be different, and Chianti wine production in Tuscany therefore needs to adapt in the near future. We address the adaptation challenges and identify grape yield and quality loss as the main impact of climate change on wine production. Relocation of vineyards uphill and introducing drought-resistant varieties are considered as adaptation measures. We appraise these adaptation measures using an optimization framework, where regional wine producers maximize income subject to economic constraints including the climate change impacts on wine productivity and quality. Our simulation shows quantitatively to what extent a higher
\end{abstract}

X. Zhu $(\bowtie) \cdot$ E. C. van Ierland

Environmental Economics and Natural Resources Group,

Wageningen University, Hollandseweg 1,

$6706 \mathrm{KN}$ Wageningen, The Netherlands

e-mail: xueqin.zhu@wur.nl

E. C. van Ierland

e-mail: ekko.vanierland@wur.nl

M. Moriondo

CNR-IBIMET, Via Caproni 8, 50145 Florence, Italy

e-mail: marco.moriondo@cnr.it

\section{G. Trombi}

International Institute for Applied Systems Analysis, 2361 Laxenburg, Austria

e-mail: trombi@iiasa.ac.at

\section{Bindi}

Department of Plant, Soil and Environmental Science,

University of Florence, Florence, Italy

e-mail: marco.bindi@unifi.it degree of climate change impact demands a higher degree of adaptation. We find that a combination of the two measures provides a better strategy because it leads to higher economic efficiency. However, uncertainty regarding the efficiency of the new variety discourages the use of this new drought-resistant variety, whereas a higher efficiency would make this choice more favourable. Sensitivity analysis for time horizon and discount rate confirms the theory of investment under uncertainty, showing a shorter time horizon (or more frequent investment) provides the possibility to postpone the decision to implement adaptation measures due to the value of flexibility, while a higher discount rate leads to a later adaptation decision, because uncertainty creates a value of waiting for new information.

Keywords Chianti wine production - Adaptation to climate change - Assessment of adaptations . Optimization · Cost-benefit analysis · Uncertainty

\section{Introduction}

Wine production is an important economic activity of the agricultural sector in the Tuscany region in central Italy. It accounts for $13 \%$ of gross production of the Tuscan agricultural sector. The local brand 'Chianti' is one of the four final wine products produced in the provinces of Firenze and Siena. It enjoys a high reputation for its high quality in the world wine market. Meanwhile, viticulture in the well-known Tuscan hills contributes to tourism because of its unique landscape. The production of high-quality wine in this region is the result of the delicate equilibrium between climate, soil characteristics and grape varieties. However, climate change is expected to affect the 
components of this interaction and therefore poses a great challenge to this unique wine production area.

According to Alcamo et al. (2007), temperature can be expected to increase by $2.5-5.5{ }^{\circ} \mathrm{C}$ by 2070 and a decrease of precipitation can be expected as high as $30-45 \%$ in the Mediterranean basin. A large productivity reduction in crops is expected in the Mediterranean because of a reduction in water availability (Iglesias et al. 2011). There is extensive literature on impacts of climate change on agriculture and potential adaptation measures. It has been shown that a progressive increase in temperature above a threshold has occurred in Europe from 1950 to 2009 (Santos et al. 2012) and has affected both wine productivity and quality in the most important wine regions including Tuscany (Jones et al. 2005; Moriondo et al. 2011). Therefore, the high-quality wine producing areas are likely to shift to higher elevations to match the best climate conditions for the ripening phase (White et al. 2006; Moriondo et al. 2013). Additionally, varieties cultivated at present would have to be replaced in the future to respond to higher temperatures (Schultz 2000; Jones et al. 2005)

Despite this, there are few studies in literature that systematically assess the effectiveness and costs and benefits of adaptations in agriculture (Howden et al. 2007; Mendelsohn and Dinar 2009; Lempert and Groves 2010). Further, there are very few economic analyses of adaptation strategies for wine production in the literature (e.g. Moriondo et al. 2011; Bernetti et al. 2012). These studies focused on the damage costs of climate change on wine production, while the benefits and costs of adaptations are not evaluated and the choices of the famers on adaptation measures are not explicitly considered. For example, Bernetti et al. (2012) evaluate the probabilities of adoption of adaptation strategies without considering the possible choice of the Tuscan wine producers on the allocation of economic resources. Moriondo et al. (2011) focus on the climate change impact on gross income from wine production without evaluating the possible adaptation measures. Therefore, these studies are not directly useful for decision-making regarding climate change adaptation in wine production.

This paper adds to the literature by developing and applying a new spatially explicit economic approach to the Chianti wine production case, which can address the adaptation challenges and assess adaptation options based on an extended cost-benefit analysis (CBA). The extended CBA is presented as an optimization framework, which includes the climate change impact on farm revenue through changes in wine productivity and price due to changes in grape yields and quality. The framework thus allows the wine producer to make choices on resource allocation under uncertain climate change impacts in order to maximize income, taking into account the different costs of adaptation measures.

Following the Diagnostic Framework developed in the Mediation project (Hinkel and Bisaro 2013), our approach includes three main stages: identifying vulnerability (impacts), identifying measures and appraising options. In the first stage, a key issue is the impact of water scarcity and increasing temperature under climate change on the productivity and quality of Chianti. Although climate change generally has a beneficial effect on quality of wine worldwide (Shultz and Jones 2010; Battaglini et al. 2009; Jones and Webb 2010), the impact on Chianti in the future is unclear. Therefore, we use a modelling approach to simulate impacts under different climate scenarios. In the second stage, we quantify the capability of different adaptation measures to cope with the impacts of climate change and identify feasible measures to counterbalance the effect of warmer temperatures and lower precipitation on grape yield and quality. Based on a previous study (Moriondo et al. 2011), which is based on simulations of grape growth under climate change scenarios, two adaptation measures are identified for further analysis in this paper. In the third stage, we appraise these adaptation options using an economic analysis.

In this study, we first use six regional circulation models (RCMs) combined with an existing meteorological data set of Tuscany to simulate the grape yield and quality response to climate change. Then, we conduct an economic analysis of the two important adaptation measures: (a) relocating the grape production area uphill, where there is less climate impact on wine quality, and (b) using an "exotic" grape variety (e.g. a southern Italian variety), which is drought resistant, to replace the current grape variety. These two measures can be implemented at a short notice, and the short-term costs can be estimated. For example, relocating a vineyard uphill involves labour and capital costs and a revenue loss of 3-year zero harvest, whereas replacing with a new variety involves the additional costs for the seedlings of the new variety and the removal of previous vine. As climate change is characterized by many uncertainties, traditional CBA is not suitable for such an assessment (Zhu and van Ierland 2010). Therefore, in this study, we consider the uncertainty of the climate change impacts on grape yield (wine productivity) and wine quality (wine price) with a wide range of potential revenue loss rates in the extended CBA.

The paper is organized as follows. In the next section, we present the information on current Chianti wine, how climate change may affect the production and what adaptation measures are feasible. In Sect. 3, we present the economic model that we use to assess adaptation measures and the model application to the Tuscan wine producer. Section 4 reports the simulation results for different 
adaptation options and provides some sensitivity analyses. Section 5 concludes.

\section{Climate change impacts on wine production}

Information on Chianti production was obtained from the statistical office of Tuscany (Statistical Office Tuscany 2011). The current viticulture area for Chianti production in the provinces of Firenze and Siena is about 35,000 hectares. The annual income of the Chianti producers in 1998-2008 was about 133 million $€$. The main variable costs for the Chianti production include fertilizers, pesticides, materials, storing, seasonal employees and operation costs for machinery. The main fixed costs include fixed costs for social security, overheads costs and fixed taxes. The difference between output revenues and production costs (the sum of variable costs and fixed costs) is the net income of a wine producer, which is the remuneration of production factors such as labour and capital. Table 1 summarizes the general information of the average Chianti producers who produce wine from vineyards on two different elevations: plain $(0-100 \mathrm{~m})$ and hilly areas (100-600 m) in 1998-2008. The statistical survey reports that about 1,000 farms are located in the plain areas. Their average vineyard area is 20.45 ha, with an average revenue of $8,964 € /$ ha, of which the price of wine is $119 € /$ quintal and productivity is 75.3 quintal/ha. There are more farms $(1,800)$ in the hilly areas than in the plain areas, but with a smaller average size (8.27 ha) and higher average farm revenue $(9,345 € / \mathrm{ha})$. This corresponds with a higher product price (153 €/quintal) because of the combined effect of a higher quality of grapes and a lower productivity

Table 1 Wine production with inputs and outputs (€/ha) in different elevation belts

\begin{tabular}{llrc}
\hline & \multicolumn{2}{c}{ Elevation of vineyards } \\
\cline { 3 - 4 } & & $0-100 \mathrm{~m}$ & $100-600 \mathrm{~m}$ \\
\hline \multirow{2}{*}{ Output of wine } & 8,964 & 9,345 \\
& Other outputs & 942 & 79 \\
& Total gross production (total outputs) & 9,906 & 9,424 \\
1 & Total variable costs & 1,529 & 1,948 \\
2 & Total fixed costs & 1,790 & 3,731 \\
& Total production costs $(1+2)$ & 3,319 & 5,679 \\
3 & Net income (i.e. Total factor & 6,586 & 3,745 \\
& remunerations: $3.1+3.2+3.3)$ & & \\
3.1 & Land & 126 & 226 \\
3.2 & Capital & 98 & 149 \\
3.3 & Labour & 6,362 & 3,370 \\
& Total inputs $(1+2+3)$ & 9,906 & 9,424 \\
\hline
\end{tabular}

Source: Statistical office Tuscany (2011)
(61 quintal/ha). The price of the wine produced in the hilly area is about $30 \%$ higher than in the plain area, while productivity is $23 \%$ lower.

In order to understand the future impact of climate change on grape yield and quality of the Chianti, we first use a delta change approach (Hay et al. 2000) to empirically downscale the outputs (minimum and maximum temperature, rainfall and global radiation) of six RCMs (Hewitt and Griggs 2004) to the study area. The resulting six data sets gridded on a spatial resolution of $1 \mathrm{~km} \times 1 \mathrm{~km}$ are then used as inputs for a grapevine model specifically calibrated for Tuscany (Bindi et al. 1997) and a vintage quality model (Moriondo et al. 2011) to simulate the grape yield and quality response to climate change.

The simulations indicate that a warmer climate would affect the crop growing cycle, causing a progressive reduction of yield in 2020 and 2040. This trend is found to be more pronounced for the hilly areas (100-600 m) than for the plain areas $(0-100 \mathrm{~m})$, reflecting the higher climate sensitivity of grapevines at higher elevations (Caffarra and Eccel 2011). Figure 1 shows how grape yields in the Chianti area would change in 2020 and 2040 relative to the current level at six different elevations (from 0-100 $\mathrm{m}$ to 500-600 m) under climate scenario A1b. For example, at an average elevation $(350 \mathrm{~m})$, the grape yield is projected to decrease by $15 \%$ by 2040 compared to the current situation. In general, the higher the elevation, the higher the yield losses, ranging from $12 \%$ at $0-200 \mathrm{~m}$ to $27 \%$ at 400-600 m (average of 6 RCMs under A1b scenario).

Similarly, the grape quality and thus wine quality mainly depend on the average weather conditions, temperature and rainfall during the growing season (Jones et al.

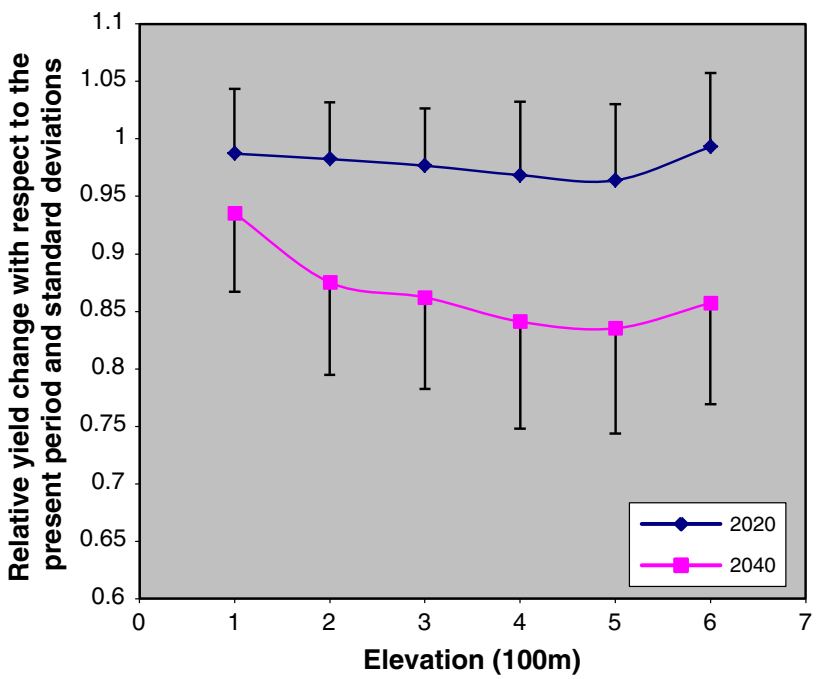

Fig. 1 Yield change and standard deviations at different elevations in 2020 and 2040 under climate change 
2005). Following the approach presented in Moriondo et al. (2011), the average temperature of the growing season and the rainfall in summer period from the six data sets are used to calculate the effect of climate change on grape quality in the Chianti region. The results are generally in good agreement with the six RCMs, showing that at present, high-quality grapes are produced in the elevation of 0-600 m, whereas in the future decades, the grape quality is expected to decrease and areas at higher elevations $(600-700 \mathrm{~m})$ are expected to produce high-quality grapes and wine.

\section{Assessment of adaptation measures under uncertainty of climate change impacts}

The optimization model for wine production considering climate change impacts

In order to model Tuscan wine production, we simplify the setting and take a social planner's perspective on resource allocation. For this reason, we aggregate wine producers in the region into a regional wine producer who produces wine in two locations (the plain and hilly areas) using factor inputs such as capital and labour, and other inputs such as fertilizers and fuel for operating machinery. The yearly income is the difference between yearly revenues and yearly production costs. Without adaptation measures, the regional wine producer aims to maximize current yearly income by allocating economic resources (i.e. labour, capital, variable and fixed costs) efficiently, i.e.

$\underset{L_{1}, L_{2}, K_{1}, K_{2}, H_{1}, H_{2}, f_{f 1} . f_{22}, f_{11}, f_{12}}{\max }=S_{1}\left[p_{1} Q_{1}-C_{1}\right]+S_{2}\left[p_{2} Q_{2}-C_{2}\right]$,

where $y$ is the current yearly income, $S_{1}$ and $S_{2}$ are the total crop areas in the plain and hilly area; $p_{1}$ and $p_{2}$ are the prices of wine; $Q_{1}$ and $Q_{2}$ are the wine outputs per ha; and $C_{1}$ and $C_{2}$ are the yearly production costs per ha from the plain and hilly area, respectively. Variables $\left(L_{1}, L_{2}, K_{1}, K_{2}\right.$, $H_{1}, H_{2}, f_{f 1}, f_{f 2}, f_{v 1}, f_{v 2}$ ) under the optimizer are the choice variables for labour, capital and land inputs per ha, and fixed and variable inputs per ha.

Given the current wine production technologies, this optimization problem is subject to the constraints of economic resources, i.e. land, labour, capital, variable and fixed costs for inputs. Regarding the specific agricultural production characteristics such as the non-substitutability between factor inputs and other inputs (e.g. seedlings, fertilizers), we use the Leontief functional form for the wine output, combined with the Cobb-Douglas technologies for intermediate inputs (c.f. Zhu et al. 2006; Zhu and van Ierland 2012). Different production technologies are used at the two different locations, and therefore, different quantities and qualities are obtained as well as different revenues per hectare (see Table 1). The production functions with different parameters at the two locations can be written as:

$Q_{1}=\min \left\{A_{c 1} f_{f 1}^{\alpha_{1}} f_{v 1}^{\left(1-\alpha_{1}\right)}, A_{f 1} L_{1}^{\beta_{1}} K_{1}^{\gamma_{1}} H_{1}^{1-\beta_{1}-\gamma_{1}}\right\}$,

$Q_{2}=\min \left\{A_{c 2} f_{f 2}^{\alpha_{2}} f_{v 2}^{\left(1-\alpha_{2}\right)}, A_{f 2} L_{2}^{\beta_{2}} K_{2}^{\gamma_{2}} H_{2}^{1-\beta_{2}-\gamma_{2}}\right\}$,

where $Q_{1}$ and $Q_{2}$ are the wine output per ha at the plain and hilly area, respectively; $A_{c 1}, A_{c 2}$ and $A_{f 1}, A_{f 2}$ are the corresponding technical parameters; $f_{f 1}, f_{f 2}$ and $f_{v 1}, f_{v 2}$ are the fixed and variable inputs per ha excluding factor inputs; $L_{1}$, $L_{2}, K_{1}, K_{2}$ and $H_{1}, H_{2}$ are the labour, capital and land inputs per ha; and $\alpha_{1}, \alpha_{2}, \beta_{1}, \beta_{2}, \gamma_{1}$ and $\gamma_{2}$ are the production parameters at the plain and hilly area, respectively.

Given these production technologies, the total costs for inputs (labour, capital, fixed costs and variable costs) for the two locations are constrained by the total resources available. For example, with $L_{1}$ for the labour costs per ha in the plain area, and $L_{2}$ in the hilly area, if the total labour costs (labour resource) $\bar{L}$ can be freely used in either location, the following constraint holds for the labour inputs for the regional wine producer:

$S_{1} L_{1}+S_{2} L_{2} \leq \bar{L}$.

Similarly, costs for other inputs (capital, land, fixed and variable costs) in two locations should also be constrained by the total resources, i.e.:

$S_{1} K_{1}+S_{2} K_{2} \leq \bar{K}$

$S_{1} H_{1}+S_{2} H_{2} \leq \bar{H}$

$S_{1} f_{f 1}+S_{2} f_{f 2} \leq \overline{f_{f}}$

$S_{1} f_{v 1}+S_{2} f_{v 2} \leq \overline{f_{v}}$,

where $\bar{K}, \bar{H}, \overline{f_{f}}$ and $\overline{f_{v}}$ are the exogenous variables for the given resources of capital, land, fixed costs and variable costs, respectively.

As Sect. 2 elaborated, climate change impacts wine productivity and quality through changes in yield and quality of grapes because both depend on the climate condition (e.g. temperature and precipitation that influence the bioaccumulation time) and the impact will be different in the plain and hilly areas. Therefore, we present the climate change impact on wine productivity by changes in wine output per ha, i.e. from the current $Q_{1}$ to the future output $Q_{1 t}$ at year $t$ in the plain area, and from $Q_{2}$ to $Q_{2 t}$ at year $t$ in the hilly area with $Q_{1 t} \leq Q_{1}$ and $Q_{2 t} \leq Q_{2}$. The impact of climate change on wine quality can be captured by the change in wine price (from the current price $p_{1}$ to the future price $p_{1 t}$ at year $t$ in the plain area, and from $p_{2}$ to $p_{2 t}$ in the hilly area with $p_{1 t} \leq p_{1}$ and $p_{2 t} \leq p_{2}$ ), because we 
consider prices as a good indicator for wine quality (Moriondo et al., 2011). Reduced productivity and quality of wine under climate change will cause a loss of revenue.

In line with Rosegrant et al. (2012), who use a constant annual declining rate of crop yield till the year 2050, we assume a decreasing and convex relation for the revenue loss in the short-medium run. This assumption is safe if no environmental regime shifts occur in the period of adaptation (e.g. $\leq 50$ years in our case). Therefore, for a constant annual revenue loss rate $c c_{1}$ in the plain area and $c c_{2}$ in the hilly area under climate change, we can obtain a series of revenues over time. Given the current farm revenue per ha in the plain area, $p_{1} Q_{1}$, the revenue per ha in the first year from now will be $\left(1-c c_{1}\right) p_{1} Q_{1}$; it will be $\left(1-c c_{1}\right)^{2} p_{1} Q_{1}$ in the second year $\ldots$, and $\left(1-c c_{1}\right)^{t} p_{1} Q_{1}$ at year $t$. Similarly for the hilly area, the revenue under climate change at year $t$ will be $\left(1-c c_{2}\right)^{t} p_{2} Q_{2}$. Formally:

$p_{1 t} Q_{1 t}=\left(1-c c_{1}\right)^{t} p_{1} Q_{1}$,

$p_{21} Q_{2 t}=\left(1-c c_{2}\right)^{t} p_{2} Q_{2}$,

where $p_{1} Q$ and $p_{2} Q_{2}$ are the current (i.e. base year) farm revenue per ha, $p_{1 t} Q_{1 t}$ and $p_{21} Q_{2 t}$ are the farm revenue per ha at year $t$ in the plain and hilly area, and parameters $c c_{1}$ and $c c_{2}$ are the annual revenue loss in the plain and hilly area. We further refer them as to climate change impact parameters.

Facing the revenue losses due to decreased wine productivity and quality under climate change, the wine producers consider investing in adaptation to decrease the climate change impact on income. Consider an adaptation measure $M_{i}$ with a yearly costs $A C_{i t}$ and an implementation period $\left[0, T_{A}\right]$. The measure may increase the revenues $\left(p_{1 t} Q_{1 t}\right.$ and $\left.p_{21} Q_{2 t}\right)$ in a longer period $t \in[0, T]$, i.e. $T \geq T_{A}$, which results in a higher total net present value of income in the period $[0, T]$. Since different adaptation measures have different costs and different impacts on revenues, the regional wine producer needs to know the total net present value of income under these measures in the period $[0, T]$ in order to make present investment decisions. The objective function is thus.

$$
\begin{aligned}
\pi= & S_{1} \sum_{t=0}^{T}\left\{\left[p_{1 t} Q_{1 t}-C_{1 t}\right] \frac{1}{(1+r)^{t}}\right\} \\
& +S_{2} \sum_{t=0}^{T}\left\{\left[p_{2 t} Q_{2 t}-C_{2 t}\right] \frac{1}{(1+r)^{t}}\right\} \\
& -\sum_{t=0}^{T_{A}}\left[A C_{i t} \frac{1}{(1+r)^{t}}\right]
\end{aligned}
$$

where $\pi$ is the total net present value of income of the producer, $C_{1 t}$ and $C_{2 t}$ are the production costs per ha at year $t$ in the plain and hilly area, respectively, $A C_{i t}$ is the costs of any adaptation measure $i$ in year $t$, and $r$ is the discount rate.
Facing $N$ different adaptation measures, the regional wine producer's problem is to maximize the total net present value of income in the period $[0, \mathrm{~T}]$ subject to the impact of climate change, adaptation costs of each measure $i(i \in N)$ and the economic constraints. The regional producer maximizes (11) subject to constraints (2)-(10), which is the optimization model for wine production considering climate change impacts and different adaptation measures. This allows to identify the best option, i.e. in this context the one which generates the highest income.

\section{Model application}

In this study, we have selected two important measures: relocating vineyards uphill (measure $A$ ) and replacing Tuscan vine in the plain area with a drought-resistant new variety (measure $B$ ). Costs of adaption include labour, capital and material costs. Vineyards also need time to produce grapes to the full capacity, which generates revenue loss in the yield recovery period. Table 2 gives the adaptation costs of these two measures and the yield recovery time for Tuscan region. For selecting the best option, we also consider a case which combines the two measures, i.e. the model specification allows all possible combinations of relocating vineyard uphill and replacing

\begin{tabular}{|c|c|c|c|c|}
\hline \multirow[t]{2}{*}{ Year } & \multicolumn{2}{|c|}{ Relocating vineyards } & \multicolumn{2}{|c|}{$\begin{array}{l}\text { Replacing vineyards with a new } \\
\text { variety }\end{array}$} \\
\hline & Costs $(\mathrm{K} € / \mathrm{ha})$ & Yields $(\%)$ & Costs $(\mathrm{K} € / \mathrm{ha})$ & Yields $(\%)$ \\
\hline 1 & 2 & 0 & 20 & 0 \\
\hline 2 & 1 & 0 & 5 & 0 \\
\hline 3 & 1 & 100 & 2 & 100 \\
\hline 4 & 0 & 100 & 0 & 100 \\
\hline 5 & 0 & 100 & 0 & 100 \\
\hline $6-50$ & 0 & 100 & 0 & 100 \\
\hline
\end{tabular}
Tuscan vine in the plain area with a drought-resistant new

Table 2 Adaptation costs per hectare and yield recovery time

Table 3 Parameters in wine production functions in two locations and exogenous variables for resources

\begin{tabular}{lllllll}
\hline & \multicolumn{6}{c}{ Parameters in wine production functions } \\
\cline { 2 - 7 } & $A_{c}$ & $A_{f}$ & $\alpha$ & $\beta$ & $\gamma$ \\
\hline Location 1 (plain area) & 5.9498 & 1.7865 & 0.5393 & 0.0191 & 0.0149 \\
Location 2 (hilly area) & 3.1566 & 3.6457 & 0.6569 & 0.0602 & 0.0397 \\
\hline & Exogenous variables (million $€$ ) & & & \\
\cline { 2 - 7 } & Labour $\bar{L}$ & Capital $\bar{K}$ & Land $\bar{H}$ & Fixed costs $\overline{f_{f}}$ & Variable costs $\overline{f_{v}}$ \\
\hline Total & 180.273 & 4.220 & 5.943 & 92.145 & 60.285 \\
\hline
\end{tabular}


variety (measures $A \& B$ ). Therefore, we apply the optimization model in Sect. 3.1 to the three cases of adaptation options: single measure $A$, single measure $B$ and the combination of measures $A \& B$.

First, parameters in the two production functions of two locations, i.e. Eqs. (2) and (3), are estimated using the information of Table 1. The exponents in Eqs. (2) and (3) are the cost shares of each input. The estimated values for the parameters are given in Table 3. Using the costs per ha for each input (Table 1) and the total area in each location, we obtain the exogenous variables of resources (the righthand sides of the constraints (4)-(8)) in Table 3.

Second, in order to make the assessment for each adaptation option, we need to choose a decision period, i.e. $T$ in Eq. (11). We select the next 50 years as the time horizon for optimization because our selected adaptation measures are likely to be effective in such a period, while a longer period is more uncertain with current knowledge, and therefore results are of less relevance. Many studies on climate change impact take this time period (e.g. Rosegrant et al. 2012) as a decision period.

Further, we need a reference to compare to when we implement adaptation measures. That is, we need to determine a baseline in which no adaptation measures are taken in the same time horizon. Finally, a comparison of the results for different measures can take place.

\section{Baseline}

Under the baseline, no adaptation measures are taken in the time horizon of 50 years. The regional wine producer consists of $n_{1}$ farms in the plain area and $n_{2}$ farms in the hilly area with average sizes of $\bar{S}_{1}$ and $\bar{S}_{2}$, respectively. Letting $A C_{i t}=0, S_{1}=\bar{S}_{1}$ and $S_{2}=\bar{S}_{2}$ in (11) and plugging (9) and (10) into (11), we can present the regional wine producer's problem in the baseline as follows:

$$
\begin{aligned}
\max _{K_{1}, K_{2}, L_{1}, L_{2}, H_{1}, H_{2}, f_{f 1}, f_{22}, f_{v 1}, f_{12}} \pi= & n_{1} \bar{S}_{1} \sum_{t=0}^{50}\left\{\left[\left(1-c c_{1}\right)^{t} p_{1} Q_{1}-C_{1 t}\right] \frac{1}{(1+r)^{t}}\right\} \\
& +n_{2} \bar{S}_{2} \sum_{t=0}^{50}\left\{\left[\left(1-c c_{2}\right)^{t} p_{2} Q_{2}-C_{2 t}\right] \frac{1}{(1+r)^{t}}\right\}
\end{aligned}
$$

subject to constraints (2)-(8), with $S_{1}=\bar{S}_{1}$ and $S_{2}=\bar{S}_{2}$.

\section{Adaptation options}

Assuming that adaptation measures are implemented at the vineyard level, which means relocating vineyards or replacing with a new variety takes place per farm, we then have the same number of farms as baseline, i.e. $n_{1}$ and $n_{2}$ in the plain and hilly area, respectively. Under measure $A$, an area $\left(S_{M A}\right)$ of vineyards per farm, or totally $n_{1} S_{M A}$ in the plain area, can be moved uphill. Therefore, a new choice variable $\left(S_{M A}\right)$ is added to the optimization model. We keep the total area for wine production constant, that is, we only use the same amount of the hilly area for relocating because of the land restrictions.

Under measure $B$, an area $\left(S_{M B}\right)$ of vineyards per farm, or totally $n_{1} S_{M B}$ in the plain area, can be replaced by the new variety. Therefore, a new choice variable $\left(S_{M B}\right)$ is added to the optimization problem. We assume that the new variety uses the similar inputs as the current Tuscan variety and is drought resistant, and therefore, there is no climate change impact on wine production for this variety in the future, i.e. $Q_{1 N t}=Q_{1 N}=Q_{1}, p_{1 N t}=p_{1 N}$, where $Q_{1 N}$ and $Q_{1 N t}$ are the wine productivity of the new variety in the current year and in year $\mathrm{t}$, while $p_{1 N}$ and $p_{1 N t}$ are their prices. Therefore, the revenue from the new variety in the future years is constant, i.e. $p_{1 N t} Q_{1 N t}=p_{1 N} Q_{1 N}$. However, the price of wine from the new variety is lower than the current Chianti, $p_{1 N} \leq p_{1}$, because of the associated low-quality and high-alcohol content (Moriondo et al. 2011). The annual revenue per ha $\left(p_{1 N} Q_{1 N}\right)$ may be lower than that of the current Tuscan variety $\left(p_{1} Q_{1}\right)$. We use the following relation:

$p_{1 N} Q_{1 N}=c_{N} \times p_{1} Q_{1}$,

where $c_{N}$ is the ratio of the per hectare revenue of the new variety to that of the existing Chianti. In our calculation, we assume $c_{N}<1$, because of its lower price. This ratio reflects the economic efficiency of the new variety relative to the existing variety because their production inputs are similar.

For the case of combining measure $A$ and $B, n_{1} S_{M A}$ is the total area of vineyards moved uphill, $n_{1} S_{M B}$ is the total area replaced by the new variety, and $n_{1}\left(\bar{S}_{1}-S_{M A}-S_{M B}\right)$ is the total non-adapted area of vineyards in the plain area. As such, we can specify the general optimization model as follows:

$$
\begin{aligned}
\pi= & n_{1}\left(\bar{S}_{1}-S_{M A}-S_{M B}\right) \sum_{t=0}^{50}\left\{\left[\left(1-c c_{1}\right)^{t} p_{1} Q_{1}-C_{1 t}\right] \frac{1}{(1+r)^{t}}\right\} \\
& +n_{1} S_{M B} \sum_{t=3}^{50}\left\{\left[p_{1 N} Q_{1 N}-C_{1 t}\right] \frac{1}{(1+r)^{t}}\right\} \\
& +n_{2} \bar{S}_{2} \sum_{t=0}^{50}\left\{\left[\left(1-c c_{2}\right)^{t} p_{2} Q_{2}-C_{2 t}\right] \frac{1}{(1+r)^{t}}\right\} \\
& +n_{1} S_{M A} \sum_{t=3}^{50}\left\{\left[\left(1-c c_{2}\right)^{t} p_{2} Q_{2}-C_{2 t}\right] \frac{1}{(1+r)^{t}}\right\} \\
& -n_{1} S_{M A} \sum_{t=0}^{3}\left\{U C_{t}\left(M_{A}\right) \frac{1}{(1+r)^{t}}\right\} \\
& -n_{1} S_{M B} \sum_{t=0}^{3}\left\{U C_{t}\left(M_{B}\right) \frac{1}{(1+r)^{t}}\right\}
\end{aligned}
$$


where $U C_{t}\left(M_{A}\right)$ and $U C_{t}\left(M_{B}\right)$ are the per-hectare-based adaptation costs for measure $A$ and $B$ at year $t$, respectively (see Table 2). This optimization problem is to choose the allocation of resources and the relocating and replacing areas $\left(S_{M A}\right.$ and $S_{M \mathrm{~B}}$ ), subject to the production technologies (Eqs. 2, 3 and 13) and resource constraints (Eqs. 4-8). Considering the same inputs per ha for the new variety as the current Tuscan variety and using relevant areas in the two locations, the constraints of resources can be rewritten as:

$n_{1}\left(\bar{S}_{1}-S_{M A}-S_{M B}\right) L_{1}+n_{1} S_{M B} L_{1}+\left(n_{2} \bar{S}_{2}+n_{1} S_{M A}\right) L_{2} \leq \bar{L}$

$n_{1}\left(\bar{S}_{1}-S_{M A}-S_{M B}\right) K_{1}+n_{1} S_{M B} K_{1}+\left(n_{2} \bar{S}_{2}\right.$

$\left.+n_{1} S_{M A}\right) K_{2} \leq \bar{K}$

$n_{1}\left(\bar{S}_{1}-S_{M A}-S_{M B}\right) H_{1}+n_{1} S_{M B} H_{1}+\left(n_{2} \bar{S}_{2}\right.$

$\left.+n_{1} S_{M A}\right) H_{2} \leq \bar{H}$

$n_{1}\left(\bar{S}_{1}-S_{M A}-S_{M B}\right) f_{f 1}+n_{1} S_{M B} f_{f 1}+\left(n_{2} \bar{S}_{2}\right.$

$\left.+n_{1} S_{M A}\right) f_{f 2} \leq \overline{f_{f}}$

$n_{1}\left(\bar{S}_{1}-S_{M A}-S_{M B}\right) f_{v 1}+n_{1} S_{M B} f_{v 1}+\left(n_{2} \bar{S}_{2}\right.$

$\left.+n_{1} S_{M A}\right) f_{v 2} \leq \overline{f_{v}}$

Objective function (14) with Eqs. (2)-(3), (13), (15)-(19) as constraints forms the most general optimization model for wine production under climate change and adaptations.

If we simply let $S_{M B}=0$ in Eqs. (14)-(19), then we obtain the model for measure $A$. Similarly, if we let $S_{M A}=0$, then we have the model for measure $B$. The objective functions for single measure $A$ and $B$, respectively, can be written as follows:

Measure A: relocating vineyards uphill

$$
\begin{aligned}
\pi= & n_{1}\left(\bar{S}_{1}-S_{M A}\right) \sum_{t=0}^{50}\left\{\left[\left(1-c c_{1}\right)^{t} p_{1} Q_{1}-C_{1 t}\right] \frac{1}{(1+r)^{t}}\right\} \\
& +n_{2} \bar{S}_{2} \sum_{t=0}^{50}\left\{\left[\left(1-c c_{2}\right)^{t} p_{2} Q_{2}-C_{2 t}\right] \frac{1}{(1+r)^{t}}\right\} \\
& +n_{1} S_{M A} \sum_{t=3}^{50}\left\{\left[\left(1-c c_{2}\right)^{t} p_{2} Q_{2}-C_{21}\right] \frac{1}{(1+r)^{t}}\right\} \\
& -n_{1} S_{M A} \sum_{t=0}^{3}\left\{U C_{t}\left(M_{A}\right) \frac{1}{(1+r)^{t}}\right\}
\end{aligned}
$$

Measure B: replacing Tuscan vine in the plain area with a new variety

$$
\begin{aligned}
& \max _{K_{1}, K_{2}, L_{1}, L_{2}, L D_{1}, L D_{2}, f_{f 1}, f_{2}, f_{v_{1}}, f_{22}, S_{M B}} \\
\pi & =n_{1}\left(\bar{S}_{1}-S_{M B}\right) \sum_{t=0}^{50}\left\{\left[\left(1-c c_{1}\right)^{t} p_{1} Q_{1}-C_{1 t}\right] \frac{1}{(1+r)^{t}}\right\} \\
& +n_{1} S_{M B} \sum_{t=3}^{50}\left\{\left[p_{1 N} Q_{1 N}-C_{1 t}\right] \frac{1}{(1+r)^{t}}\right\} \\
& +n_{2} \bar{S}_{2} \sum_{t=0}^{50}\left\{\left[\left(1-c c_{2}\right)^{t} p_{2} Q_{2}-C_{2 t}\right] \frac{1}{(1+r)^{t}}\right\} \\
& -n_{1} S_{M B} \sum_{t=0}^{3}\left\{U C_{t}\left(M_{B}\right) \frac{1}{(1+r)^{t}}\right\}
\end{aligned}
$$

This finishes the presentation of the applied models used for the simulation of the baseline and the three cases in the next section.

\section{Simulation results and discussion}

We solved the optimization models for the baseline and the three cases using GAMS software. We assumed that the production costs per hectare over time in two elevations $\left(C_{1}, C_{2 t}\right)$ were fixed, which equalled to the production costs at the base year $\left(C_{1}\right.$ and $C_{2}$, which are $3,320 €$ and $5,679 €$, respectively). For the discount rate $r$, we chose $3.5 \%$ for the next 50 years, adapting basically from Treasury (2003). Climate change uncertainty may lead to uncertain climate change impacts on wine production in terms of productivity and quality, and we use different values of the annual revenue loss rate in simulation to capture climate change uncertainty. In Rosegrant et al. (2012), the negative impact of climate change on crop yield is assumed to be annually $2 \%$ by 2050 . Based on the impact identified in Sect. 2, the yield loss is about $27 \%$ by 2040 combined with a price decrease $50 \%$ due to lower quality compared to the current situation (year 2010). This gives an average annual revenue loss of $2.2 \%$. But this result is only based on one climate change scenario. Therefore, we use a wide range of annual revenue loss rates (i.e. 2-5\%) for capturing the uncertain climate change impacts in the plain area. In the hilly area, there is a larger negative impact on yield but with an increasing quality. Therefore, we used a constant minor annual revenue loss rate $(0.2 \%)$, considering that the relative price of wine 


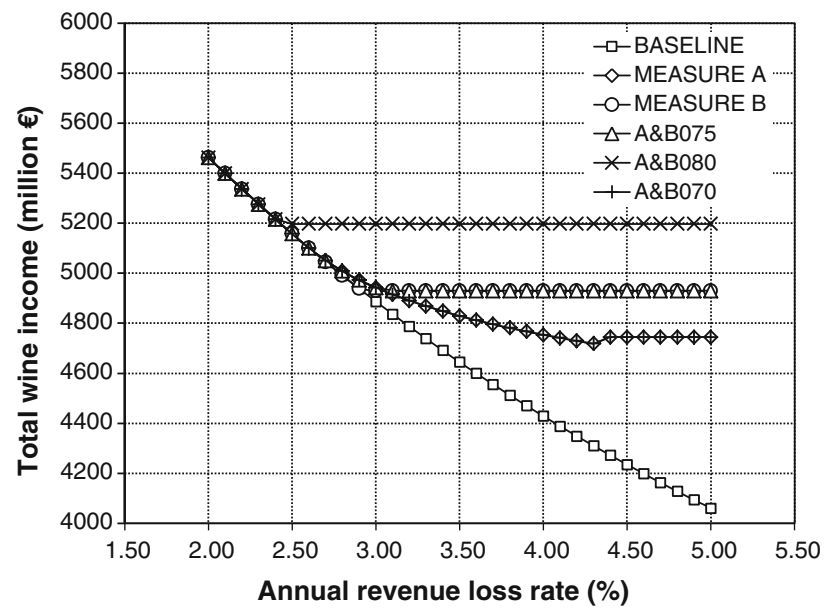

Fig. 2 Net present value of total income for different adaptation measures under different climate impact parameters reflected by different annual revenue loss rates

from the hilly areas is $30 \%$ higher than that from the plain area and yield may decrease by $23 \%$ in 50 years (see Fig. 1). ${ }^{1}$ Below we report the results.

Baseline

We now solve the model (12) with constraints (2)-(8) and $S_{1}=\bar{S}_{1}$ and $S_{2}=\bar{S}_{2}$ for the baseline. The baseline net present value of the income of the regional wine producer in next 50 years under different values of climate impact parameters is shown in Fig. 2. If no adaptation measures are taken and if the climate change impact on revenue due to yield and quality decrease is $2 \%$ per year, the net present value of the total income of the Tuscan wine farmers for the next 50 years is estimated at 5,464 million $€$, which is on average 109 million $€$ per year. If the impact parameter increases to $3 \%$, the net present value of the total income is 4,887 million $€$, which is 97.7 million $€$ per year. This means an average loss of 11.3 million $€$ per year if the climate impact parameter is increased by one percentage point. Higher climate change impacts lead to lower income.

Adaptation option 1: relocating vineyards to uphill (measure $A$ )

We now solve the model (20) with constraints (2)-(3), (13), (15)-(19) and $S_{M B}=0$ for the adaptation option of moving the vineyards uphill. The adaptation results

\footnotetext{
1 These parameters are, to the best of our knowledge, sufficiently reasonable and representative in order to allow us to illustrate the adaptation dilemmas facing wine producers. Further research will be required to provide better information on the values of the model parameters.
}

Table 4 Adaptation decisions for different options under different revenue loss rates due to climate change

\begin{tabular}{|c|c|c|c|c|c|c|c|}
\hline \multirow{2}{*}{$\begin{array}{l}\text { Revenue } \\
\text { loss rate } \\
(\%)\end{array}$} & \multicolumn{2}{|c|}{ Measure $A$} & \multicolumn{2}{|c|}{ Measure $B$} & \multicolumn{3}{|c|}{ Measure $A \& B$} \\
\hline & $A(\%)$ & $\begin{array}{l}\text { NO- } \\
\text { AD } \\
(\%)\end{array}$ & $B(\%)$ & $\begin{array}{l}\text { NO- } \\
\text { AD } \\
(\%)\end{array}$ & $A(\%)$ & $B(\%)$ & $\begin{array}{l}\mathrm{NO}- \\
\mathrm{AD} \\
(\%)\end{array}$ \\
\hline 2.0 & 0 & 100 & 0 & 100 & 0 & 0 & 100 \\
\hline 2.1 & 0 & 100 & 0 & 100 & 0 & 0 & 100 \\
\hline 2.2 & 0 & 100 & 0 & 100 & 0 & 0 & 100 \\
\hline 2.3 & 0 & 100 & 0 & 100 & 0 & 0 & 100 \\
\hline 2.4 & 0 & 100 & 0 & 100 & 0 & 0 & 100 \\
\hline 2.5 & 0 & 100 & 0 & 100 & 0 & 0 & 100 \\
\hline 2.6 & 0 & 100 & 0 & 100 & 0 & 0 & 100 \\
\hline 2.7 & 10 & 90 & 0 & 100 & 10 & 0 & 90 \\
\hline 2.8 & 17 & 83 & 0 & 100 & 17 & 0 & 83 \\
\hline 2.9 & 22 & 78 & 0 & 100 & 22 & 0 & 78 \\
\hline 3.0 & 25 & 75 & 100 & 0 & 25 & 0 & 75 \\
\hline 3.1 & 28 & 72 & 100 & 0 & 5 & 94 & 1 \\
\hline 3.2 & 30 & 70 & 100 & 0 & 5 & 94 & 1 \\
\hline 3.3 & 32 & 68 & 100 & 0 & 5 & 94 & 1 \\
\hline 3.4 & 33 & 67 & 100 & 0 & 5 & 94 & 1 \\
\hline 3.5 & 34 & 66 & 100 & 0 & 5 & 94 & 1 \\
\hline 3.6 & 35 & 65 & 100 & 0 & 5 & 94 & 1 \\
\hline 3.7 & 36 & 64 & 100 & 0 & 5 & 94 & 1 \\
\hline 3.8 & 37 & 63 & 100 & 0 & 5 & 94 & 1 \\
\hline 3.9 & 38 & 62 & 100 & 0 & 5 & 94 & 1 \\
\hline 4.0 & 38 & 62 & 100 & 0 & 5 & 94 & 1 \\
\hline 4.1 & 39 & 61 & 100 & 0 & 5 & 94 & 1 \\
\hline 4.2 & 39 & 61 & 100 & 0 & 5 & 94 & 1 \\
\hline 4.3 & 40 & 60 & 100 & 0 & 5 & 94 & 1 \\
\hline 4.4 & 78 & 22 & 100 & 0 & 5 & 94 & 1 \\
\hline 4.5 & 78 & 22 & 100 & 0 & 5 & 94 & 1 \\
\hline 4.6 & 78 & 22 & 100 & 0 & 5 & 94 & 1 \\
\hline 4.7 & 78 & 22 & 100 & 0 & 5 & 94 & 1 \\
\hline 4.8 & 78 & 22 & 100 & 0 & 5 & 94 & 1 \\
\hline 4.9 & 78 & 22 & 100 & 0 & 5 & 94 & 1 \\
\hline 5.0 & 78 & 22 & 100 & 0 & 5 & 94 & 1 \\
\hline
\end{tabular}

$A(\%)$ for the percentage of vineyard area relocated uphill; $B(\%)$ for the percentage of vineyard area replaced by the new variety; and NO$\mathrm{AD}(\%)$ for the percentage of vineyard area not adapted

regarding how much should be relocated are shown in Table 4, and the resulting income is shown in Fig. 2. Table 4 shows that when annual revenue loss rate is less than $2.6 \%$, moving vineyards uphill is not an option because the benefit of moving cannot completely cover the costs. If the revenue loss rate would be as high as $2.7 \%$, then about $10 \%$ of the vine area would need to be moved uphill. This relocation will slightly increase the regional income from 5,046 to 5,049 million $€$ (Fig. 2). As the climate impact on yield and quality loss increases, 
more vineyards should be moved uphill. If the climate impact parameter is increased to $4,38 \%$ of the vineyards should be moved to the hilly area. This will increase the net income by 325 million $€$ for the period (from 4,429 to 4,754 million $€$, see Fig. 2), which is 6.5 million $€$ per year. If the parameter increases to $4.5 \%$, most of the vineyards $(78 \%)$ should be relocated to the hilly area which has an average annual gain of 10.2 million $€$. The higher the climate change impact, the more area of vineyards in the plain areas should be relocated to avoid the economic loss caused by yield and quality decrease. We observe the high economic efficiency of this adaptation measure when climate impact on yield and quality in the plain area is high.

Adaptation option 2: replacing Tuscan vine with a new southern Italy variety (measure $B$ )

We solve the model (21) with constraints (2)-(3), (13), (15)-(19) and $S_{M A}=0$ for the adaptation option of replacing vine with a new variety. Based on Moriondo et al. (2011), we assume the new variety is about $25 \%$ lower in per hectare revenue than that of the existing Tuscan variety under the current climate. The adaptation results are shown in Table 4, and the income is shown in Fig. 2. It shows that if the annual revenue loss rate is lower than $2.9 \%$, it is not necessary to replace the Tuscan vine because the adaptation costs cannot cover the benefits of the new variety. But if the climate impact parameter reaches $3 \%$, it is beneficial to replace all the plain area with the new variety. This change will increase the regional income by 42 million $€$ (from 4,887 to 4,929 million $€$ ), which is 0.8 million $€$ per year. Although the new variety produces lower quality wine, it is climate change resistant. Therefore, under stronger climate change, it is better to replace the current vine with the new variety everywhere in the plain area. For example, if the climate impact parameter is $4.0 \%$, this measure will have a larger economic gain from 4,429 to 4,929 million $€$, which is 500 million $€$ for 50 years, i.e. 10 million $€$ per year.

Adaptation option 3: combining relocating and replacing with a new variety (measures $A \& B$ )

Finally for the case in which the two measures are combined in the decision-making process, we solve the model (19) with constraints (2)-(3), (13), (15)-(19). The model results (see Table 4; Fig. 2) show a similar pattern as the single measures. The higher the value of the climate impact parameter, the more area of vineyards would have to be adapted (moved or replaced). Under the given technology of the new variety $\left(c_{N}=0.75\right)$ and the given technologies of Chianti in the plain and hilly area, both measures can be taken simultaneously. If the revenue loss rate in the plain area is as high as $2.7 \%$, it would be worthwhile to move about $10 \%$ of the area uphill. Up to $3 \%$, relocating vineyards can be the only measure. However, further increase in the climate impact on revenue will need to use the two measures. If the revenue loss rate increases to $3.1 \%$, it is better to move $5 \%$ of the vineyards uphill and replace $94 \%$ of the area with the new variety. This combination would increase the income by 15 million $€$ as compared to the single measure of relocation $(4,915$ vs. 4,930 million $€$ ) and by one million $€$ as compared to the single measure of the new variety (4,929 and 4,930 million $€)$, because the resources can be used more efficiently. If the impact parameter is $4 \%$, the gain of combining the two measures would be 177 million $€(4,753$ vs. 4,930 million $€)$, which is more than 3.5 million $€$ per year, compared to the single measure of relocation.

It is worthwhile to compare the income in order to make the best adaptation strategy when different adaptation measures are considered. Figure 2 shows an overview on the net present value of total wine income in the 50-year period for different adaptation options (noted as Measure $A$, Measure $B, A \& B 075$ ) under different values of the climate impact parameter. It indicates clearly what measure to choose under different degrees of climate change.

\section{Sensitivity analysis}

As discussed above, the economic efficiency of the new variety is uncertain. It is interesting to see how the relative efficiency of the new variety influences the choice of the composition of the two measures. Using a higher or lower value for the efficiency of the new variety (e.g. $c_{N}=0.70$ and $c_{N}=0.80$ ), we found the results on the choice of adaptation measures (Table 5) and on income (noted as $A \& B 070$ and $A \& B 080$ in Fig. 2).

If the new variety would be less efficient (e.g. the revenue from the new variety would be only $70 \%$ of the current revenue), relocation would be the preferred option and the use of replacement could be decreased, for the same climate impact parameter. For example, for $c c_{1}=2.5 \%$, about $10 \%$ of the land should be relocated compared to $5 \%$. For $c c_{1}=3 \%, 25 \%$ of the land should be relocated, and the new variety should not be considered as an option, while in our previous case $\left(c_{N}=0.75\right)$, only $5 \%$ of the land in plain area would have to be relocated but $94 \%$ of the area should be replanted with the new variety. However, if the new variety would be more efficient $\left(c_{N}=0.80\right)$, this measure would become the overall best choice under climate change (see Fig. 2). For example, if the climate impact parameter $c c_{1}$ would be as high as $2.5 \%$, the current variety should be replaced on $100 \%$ of the land (Table 5). 
Table 5 Sensitivity analysis of the efficiency of the new variety (measure $B$ ) for adaptation decisions

\begin{tabular}{|c|c|c|c|c|c|c|c|c|c|}
\hline \multirow{2}{*}{$\begin{array}{l}\text { Revenue loss } \\
\text { rate }(\%)\end{array}$} & \multicolumn{3}{|c|}{$C_{N}=0.75$} & \multicolumn{3}{|c|}{$C_{N}=0.80$} & \multicolumn{3}{|c|}{$C_{N}=0.70$} \\
\hline & $A(\%)$ & $B(\%)$ & $\begin{array}{l}\text { NO-AD } \\
(\%)\end{array}$ & $A(\%)$ & $B(\%)$ & $\begin{array}{l}\text { NO-AD } \\
(\%)\end{array}$ & $A(\%)$ & $B(\%)$ & $\begin{array}{l}\text { NO-AD } \\
(\%)\end{array}$ \\
\hline 2.0 & 0 & 0 & 100 & 0 & 0 & 100 & 0 & 0 & 100 \\
\hline 2.1 & 0 & 0 & 100 & 0 & 0 & 100 & 0 & 0 & 100 \\
\hline 2.2 & 0 & 0 & 100 & 0 & 0 & 100 & 0 & 0 & 100 \\
\hline 2.3 & 0 & 0 & 100 & 0 & 0 & 100 & 0 & 0 & 100 \\
\hline 2.4 & 0 & 0 & 100 & 0 & 0 & 100 & 0 & 0 & 100 \\
\hline 2.5 & 0 & 0 & 100 & 0 & 100 & 0 & 0 & 0 & 100 \\
\hline 2.6 & 0 & 0 & 100 & 0 & 100 & 0 & 0 & 0 & 100 \\
\hline 2.7 & 10 & 0 & 90 & 0 & 100 & 0 & 10 & 0 & 90 \\
\hline 2.8 & 17 & 0 & 83 & 0 & 100 & 0 & 17 & 0 & 83 \\
\hline 2.9 & 22 & 0 & 78 & 0 & 100 & 0 & 22 & 0 & 78 \\
\hline 3.0 & 25 & 0 & 75 & 0 & 100 & 0 & 25 & 0 & 75 \\
\hline 3.1 & 5 & 94 & 1 & 0 & 100 & 0 & 28 & 0 & 72 \\
\hline 3.2 & 5 & 94 & 1 & 0 & 100 & 0 & 30 & 0 & 70 \\
\hline 3.3 & 5 & 94 & 1 & 0 & 100 & 0 & 32 & 0 & 68 \\
\hline 3.4 & 5 & 94 & 1 & 0 & 100 & 0 & 33 & 0 & 67 \\
\hline 3.5 & 5 & 94 & 1 & 0 & 100 & 0 & 34 & 0 & 66 \\
\hline 3.6 & 5 & 94 & 1 & 0 & 100 & 0 & 35 & 0 & 65 \\
\hline 3.7 & 5 & 94 & 1 & 0 & 100 & 0 & 36 & 0 & 64 \\
\hline 3.8 & 5 & 94 & 1 & 0 & 100 & 0 & 37 & 0 & 63 \\
\hline 3.9 & 5 & 94 & 1 & 0 & 100 & 0 & 38 & 0 & 62 \\
\hline 4.0 & 5 & 94 & 1 & 0 & 100 & 0 & 38 & 0 & 62 \\
\hline 4.1 & 5 & 94 & 1 & 0 & 100 & 0 & 39 & 0 & 61 \\
\hline 4.2 & 5 & 94 & 1 & 0 & 100 & 0 & 39 & 0 & 61 \\
\hline 4.3 & 5 & 94 & 1 & 0 & 100 & 0 & 40 & 0 & 60 \\
\hline 4.4 & 5 & 94 & 1 & 0 & 100 & 0 & 78 & 0 & 22 \\
\hline 4.5 & 5 & 94 & 1 & 0 & 100 & 0 & 78 & 0 & 22 \\
\hline 4.6 & 5 & 94 & 1 & 0 & 100 & 0 & 78 & 0 & 22 \\
\hline 4.7 & 5 & 94 & 1 & 0 & 100 & 0 & 78 & 0 & 22 \\
\hline 4.8 & 5 & 94 & 1 & 0 & 100 & 0 & 78 & 0 & 22 \\
\hline 4.9 & 5 & 94 & 1 & 0 & 100 & 0 & 78 & 0 & 22 \\
\hline 5.0 & 5 & 94 & 1 & 0 & 100 & 0 & 78 & 0 & 22 \\
\hline
\end{tabular}

Our analysis so far is based on a fixed time period of optimization (decision-making period) of 50 years. We also conduct a sensitivity analysis for this parameter using 30,40 and 60 years to understand how the timing of adaptation measures will influence our results. The simulation results under given efficiency of measure $B\left(c_{N}=0.75\right)$ show that a longer period of optimization period favours adaptation at a lower climate impact parameter (i.e. annual revenue loss rate at plain area) starting with measure $A$ and will switch to measure $B$ as climate change impact increases. For a shorter decisionmaking period, or the opportunity of having more frequent investment in a given time period, adaptation measures take place at a higher climate impact parameter (i.e. annual revenue loss rate at plain area), implying a longer waiting time. This is consistent with the theory of investment under uncertainty (Dixit and Pindyck 1994), where flexibility (more frequent investment possibilities) provides the possibility to postpone the decision to implement the adaptation measures. In all the cases, measure $A$ is the first measure to be chosen due to lower adaptation costs.

For the sensitivity of the discount rate, we use a lower (3\%) and a higher discount rate $(5 \%)$ for simulation. A lower discount rate leads to adapt at a lower climate impact parameter, because future costs and benefits are valued higher and adaptation takes place at an earlier stage, while a higher discount rate leads to adapt at a higher climate impact parameter, because uncertainty creates a value of waiting for new information. As far as the choice of adaptation measures under different discount rates is 
concerned, measure $B$ would be favoured at a low climate change impact parameter, while measure $A$ is preferred at a high climate change impact parameter. When future is highly valued (i.e. a low discount rate), measure $B$ would be first chosen because it brings more (constant) benefits in the future than measure $A$ although it is more expensive in the implementation period. Under a high discount rate, measure $A$ would first be chosen, because measure $A$ is cheaper than measure $B$ in the short period of implementation, although it brings less net present value related to future benefits than measure $B$.

\section{Discussion}

The above analysis is based on the maximization of the direct income from wine production. We did not consider the indirect benefit of the viticulture landscape such as tourism income in Tuscany. Besides, we only considered the options which will keep the wine production in Tuscany because of the strong preference of the stakeholders for maintaining wine production, even if other opportunities such as switching to other crops or switching production to other regions might bring higher economic welfare.

\section{Concluding remarks}

Following the Diagnostic Framework developed in the Mediation project, we first used the simulation model of wine production under climate change scenarios to identify the vulnerability of wine production under climate change: the impact on grape yield/wine productivity and wine quality. Then we identified possible measures for dealing with climate change impacts: relocating vineyard uphill and replacing the current variety. On the basis of this, we then applied an optimization framework incorporating the climate change impact on grape yield/wine productivity and wine quality and the costs of adaptation measures, to analyse adaptation options. Using the framework, we solved the choice of adaptation measures and the extent to which a combination of the two measures is optimal over a certain decision period (i.e. 50 years) for the adaptation situations of Chianti production. The proposed approach addressed various aspects of the issue of when-where-how to adapt in viticulture.

Our simulations show quantitatively to what extent a higher degree of climate change demands a higher degree of adaptation. When the climate impact parameter (i.e. annual revenue loss rate due to grape yield and quality loss) reaches around $3 \%$, Tuscan wine production needs to take adaptation measures. With the possibility of combining the two measures, relocating should be the first choice for the case of relatively low climate change impact and then gradually increase the replacement of the variety, because of the greater efficiency of the new variety under a changed climate. In the Tuscan case, only about $5 \%$ of the vineyard area would be relocated uphill and the remainder would be replaced with the new variety if the annual revenue loss rate would reach $3 \%$. However, this result is based on the assumption that the new variety has at least $75 \%$ of the current Chianti. If the revenue of the new variety would be no higher than $70 \%$ of the current Chianti, more vineyards in the plain area should be relocated uphill. Otherwise, if the efficiency of the new variety would be higher than $80 \%$ of the current Chianti, it is better to solely choose the new variety.

However, uncertain efficiency of the new variety discourages the use of the new drought-resistant variety, while a higher efficiency would favour this choice to larger extent. Sensitivity analysis for time horizon and discount rate confirms the theory of investment under uncertainty, showing a shorter time horizon (or the opportunity of having more frequent investment) provides the possibility to postpone the decision to implement adaptation measures due to the value of flexibility, while a higher discount rate leads to a later adaptation decision, because uncertainty creates a value of waiting for new information.

For decision-making under climate change uncertainty in this adaptation situation, it is generally recommendable to use a combination of the adaptation measures starting with relocating, because the benefit of a new variety is not yet certain. More work is needed to include detailed information on climate impacts on grape yield/wine productivity and quality for specific varieties under different climate change scenarios.

Methodologically, our study shows that model-based approaches can be used in practice to evaluate a variety of adaptation options. The analysis shows consistent results under different levels of climate change impacts, indicating the robustness of the model. Using simulation models for different scenarios can provide decision-makers with information about plausible futures under climate change uncertainty and possible response measures. However, indirect benefits of adaptation measures are not considered in the current optimization model because it is difficult to quantify them and we focus on net benefit optimization. For capturing the indirect benefits of adaptation, we may need a general equilibrium model to quantity the economywide impacts of each adaptation measure. Our analysis can only indicate which option provides the highest net direct benefits. Nevertheless, we can expect that if we include any positive indirect benefit to the model, it will compensate some adaptation costs and thus enhance the adaptation possibility at a lower cost for each measure. Furthermore, our study did not consider the possible expansion of the 
wine cultivation area, which requires an economy-wide analysis for the trade-offs of land-use changes. This is beyond the scope of this paper and deserves a more elaborated study in order to optimally allocate the economic resources in the region.

Acknowledgments This study is supported by the EU FP7 Mediation project under contract no. 244012. We are grateful for the very useful comments on the first draft from Rob Swart, Sandy Bisaro, Christian Siderius and Erik van Slobbe. Two anonymous reviewers and the editor are acknowledged for providing very useful comments for improving the readability of this paper. The comments made on the draft of this paper by Adam Walker are highly appreciated.

\section{References}

Alcamo J, Moreno JM, Nováky B, Bindi M, Corobov R, Devoy RJN, Giannakopoulos C, Martin E, Olesen JE, Shvidenko A (2007) Europe, climate change 2007 impacts, adaptation and vulnerability. In: Parry ML, Canziani OF, Palutikof JP, van der Linden PJ, Hanson CE (eds) Contribution of working group II to the fourth assessment report of the intergovernmental panel on climate change. Cambridge University Press, Cambridge, UK

Battaglini A, Barbeau G, Bindi M, Badeck FW (2009) European winegrowers' perceptions of climate change impact and options for adaptation. Reg Environ Change 9:61-73

Bernetti I, Menghini S, Marinelli N, Sacchelli S, Sottini VA (2012) Assessment of climate change impact on viticulture: economic evaluations and adaptation strategies analysis for the Tuscan wine sector. Wine Econ Policy 1:73-86

Bindi M, Miglietta F, Gozzini B, Orlandini S, Seghi L (1997) A simple model for simulation of growth and development in grapevine (Vitis vinifera L.) I. Model description. Vitis 36:67-71

Caffarra A, Eccel E (2011) Projecting the impacts of climate change on the phenology of grapevine in a mountain area. Aust $\mathrm{J}$ Grape Wine Res 17:52-61

Dixit AK, Pindyck RS (1994) Investment under uncertainty. Princeton University Press, Princeton

Hay LE, Wilby RL, Leavesley GH (2000) A comparison of delta change and downscaled GCM scenarios for three mountainous basins in the United States. J Am Water Res Assoc 36:387-397

Hewitt CD, Griggs DJ (2004) Ensembles-based predictions of climate changes and their impacts. Eos Trans Am Geophys Union 85:556. doi:10.1029/2004EO520005

Hinkel J, Bisaro A (2013) Methodological choices in problemoriented adaptation research: a diagnostic framework. Deliverable 4.5 of the Mediation project

Howden M, Tubiello FN, Chhetri N, Dunlop M (2007) Adapting agriculture to climate change. PNAS 104:19691-19696
Iglesias A, Mougou R, Moneo M, Quiroga S (2011) Towards adaptation of agriculture to climate change in the Mediterranean. Reg Environ Change 11(Suppl 1):S159-S166

Jones GV, Webb LB (2010) Climate change, viticulture, and wine: challenges and opportunities. J Wine Res 21:103-106

Jones GV, White MA, Cooper OR, Storchmann K (2005) Climate change and global wine quality. Clim Chang 73:319-343

Lempert RJ, Groves DG (2010) Identifying and evaluating robust adaptive policy response to climate change for water management agencies in the American west. Technol Forecast Social Changes 77:960-974

Mendelsohn R, Dinar A (2009) Climate change and agriculture: an economic analysis of global impacts, adaptation, and distributional effects. Edward Elgar Publishing, England

Moriondo M, Bindi M, Fagarazzi C, Ferrise R, Trombi G (2011) Framework for high-resolution climate change impact assessment on grapevines at a regional scale. Reg Environ Change 11:553-567

Moriondo M, Jones GV, Bois B, Dibari C, Ferrise R, Trombi G, Bindi M (2013) Projected shifts of wine regions in response to climate change. Clim Change 119:825-839

Rosegrant MW and the IMPACT Development Team (2012) International model for policy analysis of agricultural commodities and trade (IMPACT) model description. International Food Policy Research Institute, Washington DC

Santos JA, Malheiro AC, Pinto JG, Jones GV (2012) Macroclimate and viticultural zoning in Europe: observed trends and atmospheric forcing. Clim Res 51:89-103

Schultz HR (2000) Climate change and viticulture: a European perspective on climatology, carbon dioxide and UV-B effects. Aust J Grape Wine Res 6:2-12

Shultz HR, Jones GV (2010) Climate induced historic and future changes in viticulture. J Wine Res 21:137-145

Statistical office Tuscany (2011) Wine production information. Tuscan region, Italy

Treasury HM (2003) The green book, annex 6: discount rate. The Stationery Office, London

White MA, Diffenbaugh NS, Jones GV, Pal JS, Giorgi F (2006) Extreme heat reduces and shifts United States premium wine production in the 21st century. PNAS 103(30):11217-11222

Zhu X, van Ierland EC (2010) Report on review of available methods for cost assessment. Deliverable 3.1 from the MEDIATION project, Wageningen University, Sep 2010, p 38

Zhu X, van Ierland EC (2012) Economic modelling for water quantity and quality management: a welfare program approach. Water Res Manag 26:2491-2511

Zhu X, van Wesenbeeck L, van Ierland EC (2006) Impacts of novel protein foods on sustainable food production and consumption: lifestyle change and environmental policy. Environ Res Econ 35:59-87 